\title{
Does Indian Spot Electricity Price Series Exhibit Inverse-Leverage Effect?
}

\author{
G. P. Girish ${ }^{1,2}$, S. Vijayalakshmi1,2 \\ ${ }^{1}$ Department of Finance, IBS Hyderabad, IFHE University (a Deemed To-Be-University under Section 3 of UGC Act 1956), \\ Telangana State, India \\ ${ }^{2}$ IBS Hyderabad, IFHE University (a Deemed To-Be-University under Section 3 of UGC Act 1956), Telangana State, India \\ Email: gpgirish.ibs@gmail.com
}

How to cite this paper: Girish, G.P. and Vijayalakshmi, S. (2018) Does Indian Spot Electricity Price Series Exhibit Inverse-Leverage Effect? Theoretical Economics Letters, 8, 234-240.

https://doi.org/10.4236/tel.2018.83017

Received: December 1, 2017

Accepted: February 6, 2018

Published: February 9, 2018

Copyright $\odot 2018$ by authors and Scientific Research Publishing Inc. This work is licensed under the Creative Commons Attribution International License (CC BY 4.0).

http://creativecommons.org/licenses/by/4.0/

\begin{abstract}
In this study, we investigate whether Indian Spot Electricity Price Series exhibit Inverse-Leverage effect by modeling Indian spot electricity price using ARIMA-EGARCH model using data given by Indian Energy Exchange from January $1^{\text {st }} 2014$ to $31^{\text {st }}$ December 2015 accounting for 730 days and 17,520 hourly spot prices for all the five regions of Indian electricity market. Conditional mean and conditional variance equations are estimated. The results of the study provide crucial insights for power market participants/open access consumers whose numbers have surpassed 3530 in Indian Energy Exchange to strategically plan their exposure in Indian spot electricity market.
\end{abstract}

\section{Keywords}

Spot Electricity, Indian Energy Exchange, Inverse-Leverage Effect, ARIMA-EGARCH Model

\section{Introduction}

Indian Energy Exchange and Power Exchange India Limited are the two energy/ power exchanges which are currently functional in India and are regulated under the provisions made in Power Market Regulations 2010 issued by the Central Electricity Regulatory Commission. Very akin to electricity industry restructuring by enactment of Energy Policy Act 1992 and following it up by Federal Energy Regulatory Commission Order 888 in USA, in India, the Indian Electricity Act 2003 has cemented way for electricity industry restructuring particularly promoting competition in generation, distribution and power trading and ably ushered by power market regulations. Electricity as a commodity being manmade is unrivaled since it is beyond the bounds of possibility to be stored cost- 
effectively due to its physical properties as well as meeting the demand which usually tends to illustrate strong seasonality [1] [2]. Previously vertically integrated electric utilities in most of the countries have now been deregulated into competitive markets with introduction of private players and competition [3] [4] emancipating power market participants with additional options to choose from [5] [6] [7].

Day-ahead spot electricity operates all 24 hours, 365 days of a year typically consisting of 24 hourly auctions taking place simultaneously one day in advance [8]. Spot electricity prices are further more volatile than any other commodity and are known for extreme price volatility [9]-[15]. Electricity price series exhibit certain stylized facts namely Seasonality, Mean Reversion, Volatility and Jumps/Spikes [2] [6] [8] [10] [11] [16]. Being a case, it makes it extremely relevant for modeling spot electricity prices having lead time of few hours/days. To the best of our knowledge, this is one of the few studies in literature to explore Inverse-Leverage effect of Indian spot electricity prices using ARIMA-EGARCH Model. When inverse leverage effect exists, positive shocks have a tendency to increase volatility further than negative shocks. There is an extensive agreement that spot electricity prices demonstrate inverse leverage effect [10] [17]. It would be interesting to investigate whether different regions of Indian electricity market also exhibit Inverse-Leverage effect.

North-eastern region and eastern region grids were interconnected for power transmission in October 1991. Western region and eastern region-north eastern region were interconnected for power transmission in March 2003. Northern region and eastern regional grids were interconnected for power transmission in August 2006, thereby forming the central grid operating at one single frequency. Southern region was connected to Central Grid for power transmission on $31^{\text {st }}$ December 2013, thereby achieving "One Nation-One Grid-One Frequency". Other studies in literature by Ghosh and Kanjilal [18], Girish and Tiwari [19] and Girish [2] focused on forecasting Indian spot electricity prices using data at a time when different regions of Indian electricity market were not interconnected. With growing number of power market participants/open access consumers whose numbers have surpassed 3530 in Indian Energy Exchange, the results of our study are proposed to help these power market participants strategically plan their exposure in day-ahead Indian spot electricity market. The rest of the paper is structured as follows: Section 2 discusses the data and econometric model used in our study. Section 3 presents the empirical findings and we conclude our study in section 4 .

\section{Data and Econometric Model}

Market clearing spot electricity price in a power exchange having two-sided auction is given by the "intersection of total demand curve and the total supply curve, for a given particular hour, for each region of the electricity market" [3] [6] [8]. In this study we use hourly spot electricity price data given by Indian Energy Exchange from January $1^{\text {st }} 2014$ to $31^{\text {st }}$ December 2015 accounting for 
730 days and 17,520 hourly spot prices for each of the five regions of Indian electricity market.

The benchmark model in literature for capturing mean-reversion is simple first order autoregressive model (AR (1)) as given in Equation (2.1) [20] which is nothing but discredited adaptation of Ohrstein-Uhlenbeck process [21].

$$
p_{t}=\alpha+\beta p_{t-1}+\eta_{t} \sim N I D\left(0, \sigma_{\eta}^{2}\right)
$$

An extension to this simple AR (1) model is autoregressive moving average \{ARMA $(p, q)\}$ model as given in Equation (2.2) in which present value of spot price is expressed linearly in terms of its historic values (autoregressive component) and also in terms of historic values of the noise (moving average component).

$$
\phi(B) p_{t}=\theta(B) \varepsilon_{t}
$$

where, $B$ is the backward shift operator i.e. $B^{h} p_{t}=p_{t-h}$

$\phi(B)$ is the shorthand notation for $\phi(B)=1-\phi_{1} B-\cdots-\phi_{p} B^{p}, \theta(B)$ is the shorthand notation for $\theta(B)=1+\theta_{1} B+\cdots+\theta_{q} B^{q}$.

$\phi_{1} \cdots \phi_{p}, \theta_{1} \cdots \theta_{q}$ are the coefficients of autoregressive and moving average polynomials $\varepsilon_{t}$ is independent and identically distributed noise with zero mean and finite variance.

When differencing or seasonal differencing is rendered for making spot price series stationary, autoregressive integrated moving average model (ARIMA ( $p, d$, q)) or Seasonal ARIMA model is considered as given in Equation (2.3).

$$
p_{t}=\alpha_{t}+\sum_{i=1}^{p} \varnothing_{i} p_{t-i}+\sum_{j=1}^{q} \theta_{j} \varepsilon_{t-j}+\varepsilon_{t}, \quad \varepsilon_{t} \sim \operatorname{NID}\left(0, \sigma_{\varepsilon}^{2}\right)
$$

Linear ARMA models assume constant variance and covariance function i.e. Homoskedasticity. However if non-linear dynamics are present in spot price series, Autoregressive Conditional heteroskedasticity models of Engle [22] capitulate better results. GARCH volatility model overtly models time-varying volatility process of Engle [23] as given in Equation (2.4). In GARCH, only magnitude of lagged residuals can influence conditional variance but not the direction.

$$
\sigma_{t}^{2}=\omega+\alpha \epsilon_{t-1}^{2}+\beta \sigma_{t-1}^{2}
$$

With $\alpha+\beta<1, \alpha \geq 0, \quad \beta \geq 0$ and $\omega>0$ where the ARCH factor, $\alpha$ quantifies the size of the effect and the GARCH factor, $\beta$, captures the extent of volatility which is persistent.

A high $\alpha$ would be a sign that market participants will exhibit blown up reaction for any kind of preceding price errors in a way such that expected volatility will turn out to be unstable [2] [10]. However, if the positive and negative shocks have varied impact on volatility, then, an asymmetric GARCH specification i.e. EGARCH is preferable [2] [16] as given in Equation (2.5).

$$
\log \left(\sigma_{t}^{2}\right)=\omega+\sum_{i=1}^{p} \alpha_{i} \frac{\varepsilon_{t-i}}{\sigma_{t-i}}+\sum_{k=1}^{r} \gamma_{k}\left(\frac{\varepsilon_{t-k}}{\sigma_{t-k}^{2}}\right)+\sum_{j=1}^{q} \beta_{j} \log \left(\sigma_{t-1}^{2}\right)
$$

where $\alpha+\beta<1, \quad \alpha \geq 0, \quad \beta \geq 0$ and $\omega>0$, where $\log$ of conditional variance 
$\log \left(\sigma_{t}^{2}\right)$ suggests that asymmetric effect is exponential in nature and also that forecasts of conditional variance is expected to be non-negative [16]. The asymmetry in EGARCH model is captured by $\gamma_{k}$. When inverse leverage effect exists, positive shocks have a tendency to increase volatility further than negative shocks. There is an extensive agreement that spot electricity prices demonstrate inverse leverage effect [10] [17].

\section{Empirical Findings}

Spot Electricity price series for each of the five regions of Indian electricity market is tested for existence of a unit root using standard tests ${ }^{1}$. First difference is rendered to spot price series and conditional mean equation is estimated by utilizing autocorrelation function (ACF), partial autocorrelation function (PACF) and the Correlogram which aided us in model calibration. Null hypothesis of 'no conditional heteroskedasticity' is investigated using ARCH-LM test.

Suitability of calibrated model for each region is arrived based on lowest SIC and on the basis of diagnostic checks of PACF, ACF, residuals and Ljung-Box Q-test statistics. The estimation results of the conditional mean equation and conditional variance equation for ARIMA-EGARCH $(1,1)$ is presented in Table 1 and Table 2. We find leverage effect in east, north and southern region with

Table 1. Estimation results of conditional mean equation.

\begin{tabular}{|c|c|c|c|c|c|}
\hline & East & North & North east & South & West \\
\hline \multirow[t]{2}{*}{$\mathrm{C}$} & -0.00072 & -0.00059 & -0.00129 & 0.0044 & -0.00116 \\
\hline & $(0.0013)$ & $(0.00023)^{\star *}$ & $(0.0010)$ & $(0.0035)$ & $(0.00129)$ \\
\hline \multirow[t]{2}{*}{$\operatorname{AR}(1)$} & -0.4687 & -0.5539 & -1.2889 & 0.1539 & 0.1378 \\
\hline & $(0.0524)^{\star}$ & $(0.0247)^{\star}$ & $(0.0661)^{\star}$ & $(0.1333)$ & $(0.2756)$ \\
\hline \multirow[t]{2}{*}{$\operatorname{AR}(2)$} & -0.1029 & 0.1632 & -0.07725 & & 0.2604 \\
\hline & $(0.062)^{* * *}$ & $(0.0309)^{\star}$ & $(0.1191)$ & & $(0.2317)$ \\
\hline \multirow[t]{2}{*}{$\operatorname{AR}(3)$} & 0.684 & 0.7468 & 0.5128 & & -0.2952 \\
\hline & $(0.0520)^{*}$ & $(0.0256)^{*}$ & $(0.0662)^{*}$ & & $(0.1553)^{\star *}$ \\
\hline \multirow[t]{2}{*}{ MA (1) } & 0.2555 & 0.3753 & 1.0787 & -0.4544 & -0.4414 \\
\hline & $(0.0290)^{\star}$ & $(0.0067)^{\star}$ & $(0.0766)^{\star}$ & $(-3.940)^{\star}$ & $(0.2766)$ \\
\hline \multirow[t]{2}{*}{ MA (2) } & -0.1343 & -0.3723 & -0.4646 & & -0.4203 \\
\hline & $(0.0344)^{\star}$ & $(0.0060)^{\star}$ & $(0.0819)^{\star}$ & & $(0.2267)^{\star \star}$ \\
\hline \multirow[t]{2}{*}{ MA (3) } & -0.9294 & -0.9798 & -1.0298 & & 0.3042 \\
\hline & $(0.0287)^{\star}$ & $(0.0072)^{\star}$ & $(0.0417)^{\star}$ & & $(0.2453)$ \\
\hline \multirow[t]{2}{*}{ MA (4) } & & & -0.1781 & & -0.1992 \\
\hline & & & $(0.0593)^{\star}$ & & $(0.0743)^{\star}$ \\
\hline AIC & -1.128 & -1.264 & -1.322 & -0.966 & -1.3435 \\
\hline SIC & -1.055 & -1.191 & -1.243 & -0.92 & -1.2638 \\
\hline $\mathbf{R}^{2}$ & 0.1373 & 0.1174 & 0.2167 & 0.1008 & 0.1256 \\
\hline Adj $R^{2}$ & 0.1296 & 0.1096 & 0.2085 & 0.0981 & 0.1165 \\
\hline \multicolumn{6}{|c|}{$\begin{array}{l}{ }^{*} \text { Note: Standard errors have been reported in parenthesis. Significance is denoted by }{ }^{*} \text { for } 1 \% \text { level, }{ }^{* *} \text { for } \\
5 \% \text { level and }{ }^{* * *} \text { for } 10 \% \text { level. }\end{array}$} \\
\hline \multicolumn{6}{|c|}{$\begin{array}{l}{ }^{1} \text { We used ADF test, PP test, KPSS test and Narayan and Popp (2010) test for investigating presence } \\
\text { of unit root. For the purpose of brevity the results have not been reported. Study by Vijayalakshmi et } \\
\text { al., } 2017 \text { [14] exclusively presents the results of Stationarity for similar data period. Study by Girish } \\
\text { et al., } 2018 \text { focuses exclusively on Spot electricity price discovery in Indian electricity market. }\end{array}$} \\
\hline
\end{tabular}


Table 2. Estimation results of conditional variance equation.

\begin{tabular}{cccccc}
\hline & East & North & North east & South & West \\
\hline ARCH $(\alpha)$ & 0.1843 & 0.5489 & 0.3123 & 0.2776 & 0.1716 \\
& $(0.0628)$ & $(0.0812)$ & $(0.0464)$ & $(0.0335)$ & $(0.0374)$ \\
Asymmetry $(\gamma)$ & -0.2388 & -0.0729 & 0.0994 & -0.033 & 0.04 \\
& $(0.0368)$ & $(0.0540)$ & $(0.0362)$ & $(0.0314)$ & $(0.0256)$ \\
GARCH $(\beta)$ & 0.1614 & 0.4851 & 0.8518 & 0.8642 & 0.9642 \\
& $(0.1092)$ & $(0.0877)$ & $(0.0391)$ & $(0.0140)$ & $(0.0119)$ \\
\hline
\end{tabular}

${ }^{*}$ Note: Standard errors have been reported in parenthesis.

asymmetry term $\gamma$ negative and inverse-leverage effect with asymmetry term $\gamma$ positive for west and north-eastern region at $1 \%$ significance level.

\section{Concluding Remarks}

Electricity as a commodity being man-made is unrivaled since it is beyond the bounds of possibility to be stored cost-effectively. In this study, we modeled Indian spot electricity price using ARIMA-EGARCH model $(1,1)$ by using spot electricity price data given by Indian Energy Exchange. Conditional mean and conditional variance equations were estimated. We found leverage effect in east, north and southern regions and inverse-leverage effect for west and north-eastern regions of Indian electricity market. The results of the study provide crucial insights for 3530+ power market participants/open access consumers in Indian Energy Exchange to strategically plan their exposure in day-ahead Indian spot electricity market.

\section{Acknowledgements}

This paper was presented in $13^{\text {th }}$ International Conference on Business and Finance (ICBF 2017) which was held in IBS Hyderabad in December, 2017 organized jointly by IBS Hyderabad, IFHE University, India and Gokhale Institute of Politics and Economy, Pune, India. This is a revised and expanded version of the paper.

\section{References}

[1] Weron, R. and Misiorek, A. (2008) Forecasting Spot Electricity Prices: A Comparison of Parametric and Semiparametric Time Series Models. International Journal of Forecasting, 24, 744-763. https://doi.org/10.1016/j.ijforecast.2008.08.004

[2] Girish, G.P. (2016) Spot Electricity Price Forecasting in Indian Electricity Market Using Autoregressive-GARCH Models. Energy Strategy Reviews, 11-12, 52-57. https://doi.org/10.1016/j.esr.2016.06.005

[3] Li, G., Liu, C.-C., Mattson, C. and Lawarree, J. (2007) Day-Ahead Electricity Price Forecasting in a Grid Environment. IEEE Transactions on Power Systems, 22, 266274. https://doi.org/10.1109/TPWRS.2006.887893

[4] Amjady, N. and Daraeepour, A. (2009) Design of Input Vector for Day-Ahead Price 
Forecasting of Electricity Markets. Expert Systems with Applications, 36, 12281-12294. https://doi.org/10.1016/j.eswa.2009.04.059

[5] Aggarwal, S.K., Saini, L.M. and Kumar, A. (2009) Electricity Price Forecasting in Deregulated Markets: A Review and Evaluation. International Journal Electrical Power \& Energy Systems, 31, 13-22. https://doi.org/10.1016/j.ijepes.2008.09.003

[6] Girish, G.P., Sashikala, P., Supra, B. and Acharya, A. (2015) Renewable Energy Certificate Trading through Power Exchanges in India. International Journal of Energy Economics and Policy, 805-808. http://www.econjournals.com/index.php/ijeep/article/view/1287

[7] Girish, G.P., Rath, B.N. and Akram, V. (2018) Spot Electricity Price Discovery in Indian Electricity Market. Renewable and Sustainable Energy Reviews, 82, 73-79. https://doi.org/10.1016/j.rser.2017.09.009

[8] Weron, R. (2006) Modeling and Forecasting Electricity Loads and Prices: A Statistical Approach. Wiley Finance Publication. http://as.wiley.com/WileyCDA/WileyTitle/productCd-047005753X.html

[9] Karakatsani, N.V. and Bunn, D.W. (2004) Modelling the Volatility of Spot Electricity Prices. 2nd Energy Risk Management Seminar.

[10] Bowden, N. and Payne, J.E. (2008) Short Term Forecasting of Electricity Prices for MISO Hubs: Evidence from ARIMA-EGARCH Models. Energy Economics, 30, 3186-3197. https://doi.org/10.1016/j.eneco.2008.06.003

[11] Girish, G.P. and Vijayalakshmi, S. (2014) Spot Electricity Price Dynamics of Indian Electricity Market. In: Jeong, H., S. Obaidat, M., Yen, N., Park, J., Eds., Advances in Computer Science and Its Applications. Lecture Notes in Electrical Engineering, Vol. 279, Springer, Berlin, Heidelberg, 1129-1135. https://doi.org/10.1007/978-3-642-41674-3_157

[12] Girish, G.P., Vijayalakshmi, S., Panda, A.K. and Rath, B.N. (2014) Forecasting Electricity Prices in Deregulated Wholesale Spot Electricity Market-A Review. International Journal of Energy Economics and Policy, 4, 32-42. http://www.econjournals.com/index.php/ijeep/article/view/621

[13] Vijayalakshmi, S. and Girish, G.P. (2015) Artificial Neural Networks for Spot Electricity Price Forecasting: A Review. International Journal of Energy Economics and Policy, 5, 1092-1097. http://www.econjournals.com/index.php/ijeep/article/view/1446

[14] Vijayalakshmi, S., Girish, G.P., Singhania, K. and Vincent, E.N. (2017) Is Indian Spot Electricity Price Series Stationary? Energy Procedia, 138, 1067-1072. https://doi.org/10.1016/j.egypro.2017.10.114

[15] Vijayalakshmi, S., Girish, G.P. and Singhania, K. (2017) Role of Renewable Energy in Indian Power Sector. Energy Procedia, 138, 1073-1078. https://doi.org/10.1016/j.egypro.2017.10.117

[16] Hickey, E., Loomis, D.G. and Mohammadi, H. (2012) Forecasting Hourly Electricity Prices Using ARMAX-GARCH Models: An Application to MISO Hubs. Energy Economics, 34, 307-315. https://doi.org/10.1016/j.eneco.2011.11.011

[17] Liu, H. and Shi, J. (2013) Applying ARMA-GARCH Approaches to Forecasting Short-Term Electricity Prices. Energy Economics, 37, 152-166.

https://doi.org/10.1016/j.eneco.2013.02.006

[18] Ghosh, S. and Kanjilal, K. (2014) Modelling and Forecasting of Day-Ahead Electricity Price in Indian Energy Exchange-Evidence from MSARIMA-EGARCH Model. International Journal of Indian Culture and Business Management, 8, 413-423. 
https://doi.org/10.1504/IJICBM.2014.060367

[19] Girish, G.P. and Tiwari, A. (2016) A Comparison of Different Univariate Forecasting Models for Spot Electricity Price in India. Economics Bulletin, 36, 1039-1057. http://www.accessecon.com/Pubs/EB/2016/Volume36/EB-16-V36-I2-P103.pdf

[20] Gibson, R. and Schwartz, E.S. (1990) Stochastic Convenience Yield and the Pricing of Oil Contingent Claims. Journal of Finance, 45, 959-976. https://doi.org/10.1111/j.1540-6261.1990.tb05114.x

[21] Knittel, C.R. and Roberts, M.R. (2005) An Empirical Examination of Restructured Electricity Prices. Energy Economics, 27, 791-817. https://doi.org/10.1016/j.eneco.2004.11.005

[22] Engle, R.F. (1982) Autoregressive Conditional Heteroscedasticity with Estimates of the Variance of United Kingdom Inflation. Econometrica, 50, 987-1007. https://doi.org/10.2307/1912773

[23] Engle, R.F. (2001) GARCH 101: The Use of ARCH/GARCH Models in Applied Econometrics. Journal of Economic Perspectives, 15, 157-168.

https://doi.org/10.1257/jep.15.4.157 